\title{
The attitudes of general dental practitioners and medical specialists to the provision of intra-oral appliances for the management of snoring and sleep apnoea
}

\author{
S. Jauhar, ${ }_{1}^{1}$ M. F. Lyons, ${ }_{1}^{2}$ S. W. Banham, ${ }_{1}^{3}$ R. Orchardson ${ }^{4}$ and E. Livingston ${ }^{5}$
}

IN BRIEF

- Provides information on the current provision of mandibular advancement appliances by a random sample of dentists.

- Summarises the opinions of medical specialists on the provision of these appliances.

- Discusses the need to fund this treatment by the National Health Service.

- Highlights the need for the further training of dentists in the provision of mandibular advancement appliances.

\section{VERIFIABLE CPD PAPER}

\begin{abstract}
Aim To determine the attitudes and awareness of dental and medical practitioners in Scotland to the provision of oral appliances for the management of snoring and sleep apnoea. Setting The questionnaire was completed by general dental practitioners randomly selected from across Scotland and by doctors specialising in sleep medicine within Scotland.

Method A questionnaire was devised and sent to 17 specialists in sleep medicine and 210 general dental practitioners, community dental service practitioners and hospital-based dental practitioners. A reply-paid envelope was included with each questionnaire. Results There were 14 replies (82\%) from specialists and 105 (50\%) from dentists. All the specialists felt that dentists had a role in the management of these patients. Of the replies from dentists, 60 (57\%) stated that they provided appliances but their screening for sleep apnoea and discussion of the side-effects of appliances varied widely. Seventy-eight dentists (74\%) expressed an interest in attending a course on the management of sleep apnoea and snoring. Conclusions The current practice of specialists and dentists in the management of obstructive sleep apnoea and socially disruptive snoring with oral appliances in Scotland is varied. Many dentists expressed a wish for further training in this area.
\end{abstract}

\section{INTRODUCTION}

The problems of snoring and obstructive sleep apnoea have received considerably increased public attention during the past 10-15 years. The noise of snoring can cause significant marital and social problems and lead to sleep deprivation for the sleep partner. ${ }^{1}$ Sleep apnoea, or more specifically obstructive sleep apnoea (OSA), is a more serious problem as the apnoeic episodes lead to reduced blood oxygen saturation and cardiovascular problems

\footnotetext{
Specialist Registrar, Department of Restorative Dentistry, Glasgow Dental Hospital and School, 378 Sauchiehall Street, Glasgow, G2 3JZ; ${ }^{2+}$ Senior Lecturer, Section of Restorative Dentistry, Dundee Dental School, Park Place, Dundee, DD1 4HR; ${ }^{3}$ Consultant, ${ }^{5}$ Specialist Registrar, Department of Respiratory Medicine Gartnavel Royal Hospital, Glasgow, G12 OYN; ${ }^{4}$ Senior Lecturer, Unit of Oral Biology, University of Glasgow, 378 Sauchiehall Street, Glasgow, G2 3JZ *Correspondence to: Dr Mervyn F. Lyons Email:m.f.lyons@dundee.ac.uk
}

\section{Refereed Paper}

Accepted 20 August 2008

DOI: 10.1038/sj.bdj.2008.1022

${ }^{\circledR}$ British Dental Journal 2008; 205: 653-657 (particularly hypertension) in the long term. ${ }^{2}$ OSA also causes significant daytime sleepiness, with impaired daytime functioning and increased risk of road traffic accidents. ${ }^{3-6}$ Uncomplicated snoring occurs in approximately $40 \%$ of the adult population in the UK and approximately $10 \%$ of these snorers have 0SA. ${ }^{7}$

Intra-oral appliances were first used for the control of snoring and OSA in Canada and the USA in the late $1980 \mathrm{~s}^{8,9}$ and in the UK in the mid-1990s..$^{10,11}$ The increased availability of intra-oral appliances, almost exclusively mandibular advancement appliances (MAA), has undoubtedly contributed to the increased public awareness of the possibility of controlling snoring and sleep apnoea. However, in the UK the provision of these appliances varies between areas and funding is still a contentious issue. In order to assist in the improvement of the service, more information is required on the views of hospital doctors specialising in sleep medicine (henceforth referred to as specialists) and general dental practitioners. Therefore a questionnaire was devised to obtain opinions on the perceived value of these appliances and the confidence of dentists to supply them.

\section{METHOD}

The questionnaire was written by one of the authors (SJ) with comments from the other authors. After various suggestions were incorporated, the questionnaire was piloted on a small scale among dentists based in hospital, community and general dental practice. A list of dentists in Scotland was then obtained from the Dentists Register of the General Dental Council and entered into a database. A random number generator was then used to select 210 dentists from this database. Questionnaires, which were anonymised, together with reply-paid envelopes, were sent to these 210 dentists and a covering letter pledged a donation of $£ 1$ to charity for each questionnaire returned. These 
questionnaires consisted of ten questions to obtain general information on the respondents and also their attitude to the provision of MAAs (Fig. 1).

Specialists with a known interest and expertise in sleep medicine were specifically selected and there were only 17 in Scotland. The questionnaire to the specialists simply consisted of five questions relating to whom they considered should provide an MAA and what screening tests should be performed in a primary care setting prior to referral (Fig. 2).

\section{RESULTS}

There were 14 replies (82\%) from the specialists and 105 (50\%) from the dentists.

\section{Replies from specialists}

There were 12 specialists in respiratory medicine and two from other specialities (not specified). All 14 thought that dentists had a role in helping patients with OSA or socially disruptive snoring. Twelve specialists (86\%) felt that dentists could be involved in the screening and referral of patients as well as the provision of appliances, with eight (57\%) believing that dentists could give lifestyle advice to patients.

\section{Replies from dentists}

There were 105 replies in total, a response rate of $50 \%$, but no attempt was made to contact non-responders. Of these 105 replies, three respondents simply stated that they had recently retired, leaving 102 responses available for analysis. However, it should be noted that some respondents did not answer every question. The returns were relatively evenly split between genders with 53 (51.9\%) male and $47(46 \%)$ female and $2(1.9 \%)$ not stated. The average age of respondents was 40 years (females) and 46 years (males).

The areas of activity of the dentists were general dental practice 77 , hospital practice (including dental specialist) 11 , community dental service (CDS) 10 , and no data was provided by four respondents. The frequency with which patients with sleep apnoea or chronic snoring were seen by these dentists varied (Table 1) but only dentists in the CDS claimed to see these patients frequently.

When dentists do see these patients in

\section{Fig. 1 Questionnaire to dentists}

1. Please indicate your area/s of practice: General Practice (including mixed, NHS and private) $\square$

Hospital (including dental specialist) $\square$ Community $\square$

2. How often do you see patients with chronic snoring or possible sleep apnoea?

Frequently $\square$

Infrequently $\square$

Occasionally $\square$

Never $\square$

3. What do you offer patients with possible sleep apnoea or chronic snoring?

(Tick all that apply):

Nothing $\square$

Lifestyle advice $\square$

Provide an appliance $\square$

Refer to sleep clinic $\square$

Refer elsewhere $\square$

4. Would you discuss any side effects of oral appliances with your patient?

Yes $\square$ No $\square$

If yes, please specify:

5. Do you currently provide patients with appliances?

Yes $\square$ No $\square$

If yes, what tests do you carry out to screen for sleep apnoea?

6. What criteria do you use to refer patients to a sleep specialist?

7. Have you attended any courses on the management of sleep apnoea or socially disruptive snoring?

8. With your current level of training, would you be comfortable providing patients with oral appliances for sleep apnoea or disruptive snoring? Yes $\square$ No $\square$

9. Would you be interested in attending a course on the dentist's role in the management of sleep disorders? Yes $\square$ No $\square$

10. Do you think that any of your patients would be interested in these appliances if you were to offer them? Yes $\square$ No $\square$ Possibly $\square$

Please add any relevant comments below:

their practice, they offered a varied service. Of the 59 respondents who provided information about their service, 10\% did not offer anything, 40\% would provide an appliance, $25 \%$ would refer to a sleep clinic and 25\% would refer to other specialist services (Tables 2 and 3).
The number of dentists who would discuss the side-effects of appliances with patients was quite evenly divided, with 27 (45\%) of the 58 respondents to this question saying that they would and $29(48 \%)$ that they would not. Details of the side-effects discussed may be seen in Table 4.

From the 60 replies to the question of whether dentists currently provide appliances, 19 (32\%) stated that they do and 41 (68\%) do not (Table 5).

The criteria used to refer patients to a sleep specialist were stated as excessive tiredness by five respondents, patient's request by six and a high Epworth score (see Fig. 3) by two. A variety of other factors were listed, including severity of symptoms, effect on lifestyle and failure of an appliance.

A relatively small percentage of dentists ( 25 out of 102 , or $24 \%$ ) had attended a course on the management of sleep apnoea or socially disruptive snoring (Table 6). When asked whether they would be comfortable providing patients with oral appliances for sleep apnoea or disruptive snoring, 76 out of 105 (72.4\%) responded that they were not comfortable, $25(23.8 \%)$ responded that they were and four $(3.8 \%)$ did not respond to this particular question (Table 7).

From the 76 responses to the question of whether they would wish to attend a course, 60 (59\%) were interested in attending a course and 21 (17\%) would not be interested in attending (Table 8). Of the 25 who responded that they were comfortable providing patients with oral appliances, 18 (72\%) were interested in attending further training and seven $(28 \%)$ were not.

Dentists were also asked whether they thought that any of their patients would be interested in these appliances if they were offered and 82 (78\%) thought that they would be, six (6\%) thought that they might possibly be interested, 10 (9\%) thought that they would not and seven (7\%) did not respond.

Finally, dentists were given the opportunity to make any further comments and these are listed in Table 9.

\section{DISCUSSION}

While this was not a large scale study, the number of responses from both 
Fig. 2 Questionnaire to specialists

1. Please indicate your specialty:

Respiratory Medicine $\square$

ENT $\square$

Other (please specify) $\square$

2. Do you think that dentists have a role in helping patients with either socially disruptive snoring or sleep apnoea? Snoring: Yes $\square$ No $\square$

Sleep apnoea: Yes $\square$ No $\square$

3. If you think "Yes" to the above question, in which areas do you think that dentists could be involved?

Screening for referral to a specialist $\square$

Lifestyle advice $\square$

Provision of appliances $\square$

Other (please specify) $\square$

4. Which tests would you like to see all primary care providers (doctors and dentists) use to screen for possible referral to a sleep specialist?

Epworth Sleepiness Scale $\square$

Symptoms of daytime somnolence $\square$

Other (please specify) $\square$

5. Which of the following is your usual practice for patients whom you consider suitable for a mandibular advancement appliance?

No involvement $\square$

Information leaflet $\square$

Provide pre-made appliance $\square$

Refer to own dentist $\square$

Refer to orthodontist $\square$

Refer elsewhere (please specify) $\square$

medical specialists and dentists was considered to be sufficient to give an indication of current practice in Scotland. The low response rate of 50\% from the dentists could possibly be an indication of the low level of importance given to this area by dentists. With regard to this low response rate, it should be pointed out that the percentage values given to the figures derived from this questionnaire are percentages of responses and so might not be representative of the whole group surveyed. Dentists in the CDS and hospital service were included in the survey because although the nature of their work is different to general dental practice, a broad overview of opinions was considered to be of value.

All of the specialists that replied indicated that they thought that dentists had a role in helping patients with obstructive sleep apnoea or socially disruptive snoring. However, the view on scope of this involvement varied, as 12 (86\%) felt that dentists could be involved in

Table 1 The frequency with which dentists see patients with possible sleep apnoea or chronic snoring $(\mathrm{n}=101)$

\begin{tabular}{l|l|l|l|l|l}
\hline Category & Infrequent & Never & Occasionally & Frequently & No data \\
\hline General & 48 & 24 & 5 & - & - \\
\hline Hospital & 3 & 8 & - & - & - \\
\hline Community & 2 & 7 & - & 1 & - \\
\hline Not recorded & 1 & 2 & - & - & 1
\end{tabular}

Table 2 Services offered to patients with possible sleep apnoea or chronic snoring

\begin{tabular}{|c|c|c|}
\hline $\begin{array}{l}\text { Total number } \\
\text { of responses }\end{array}$ & $\begin{array}{l}\text { Type of } \\
\text { practice }\end{array}$ & $\begin{array}{l}\text { Combination } \\
\text { results }\end{array}$ \\
\hline 1 & Community & 1 \\
\hline 1 & Community & $2+3+5$ \\
\hline 1 & Community & 5 \\
\hline 5 & General & 1 \\
\hline 1 & General & $1+3$ \\
\hline 7 & General & 2 \\
\hline 5 & General & $2+3$ \\
\hline 2 & General & $2+3+4$ \\
\hline 1 & General & $2+3+5$ \\
\hline 5 & General & $2+4$ \\
\hline 1 & General & $2+4+5$ \\
\hline 1 & General & $2+5$ \\
\hline 10 & General & 3 \\
\hline 2 & General & $3+4$ \\
\hline 1 & General & $3+5$ \\
\hline 4 & General & 4 \\
\hline 7 & General & 5 \\
\hline 1 & Hospital & $2+5$ \\
\hline 2 & Hospital & 3 \\
\hline 1 & Hospital & $3+5$ \\
\hline
\end{tabular}

Key: 1 = nothing; 2 = lifestyle advice; $3=$ provide an apoliance $4=$ refer to sleep clinic; $5=$ refer elsewhere

Table 3 Referral patterns of the 29 dentists who included 'referral' in their management

\begin{tabular}{l|l}
\hline Refer to & $\begin{array}{l}\text { Number of } \\
\text { dentists }\end{array}$ \\
\hline Sleep clinic & 14 \\
\hline $\begin{array}{l}\text { Dental hospital, oral surgery } \\
\text { or oral medicine }\end{array}$ & 7 \\
\hline General medical practitioner & 4 \\
\hline GDP who provides appliances & 2 \\
\hline Orthodontist & 1 \\
\hline ENT surgery & 1 \\
\hline
\end{tabular}

Table 4 Possible issues and side-effects of appliances that dentists discuss with patients

\begin{tabular}{|l|l|}
\hline Side-effect & Number \\
\hline Poor compliance & 13 \\
\hline TMJ pain & 7 \\
\hline Oral hygiene & 5 \\
\hline Lack of effectiveness & 4 \\
\hline Hyper-salivation & 2 \\
\hline Caries & 2 \\
\hline Periodontal issues & 2 \\
\hline Appliance hygiene & 1 \\
\hline Social issues & 1 \\
\hline Movement of upper anterior teeth & 1 \\
\hline Occlusal disruption & 1 \\
\hline Gagging & 1 \\
\hline Dry mouth & 1 \\
\hline
\end{tabular}

Table 5 Do you currently provide appliances?

\begin{tabular}{l|l|l|l}
\hline Category & Yes & No & No data \\
\hline General & 18 & 35 & 24 \\
\hline Hospital & 1 & 2 & 8 \\
\hline Community & - & 3 & 7 \\
\hline Not recorded & - & 1 & 3
\end{tabular}

Table 6 Details of which groups of dentists have attended a course on snoring and sleep apnoea

\begin{tabular}{|l|l|l|}
\hline Category & Yes & No \\
\hline General & 21 & 55 \\
\hline Hospital & - & 10 \\
\hline Community & 3 & 9 \\
\hline Not Recorded & 1 & 3 \\
\hline
\end{tabular}


screening, referral and construction of appliances and eight (57\%) felt that it was appropriate for dentists to give lifestyle advice. Patients of dentists, however, rarely complain of obstructive sleep apnoea or socially disruptive snoring, probably because they do not think that this is within the scope of practise of a dentist. Dentists, therefore, are not so aware of the problem. In addition, their current practice is variable if they do see these patients, with 45\% referring the patient and only 30\% providing appliances. It was encouraging to find that $40 \%$ of dentists gave lifestyle advice.

The side-effects of mandibular advancement appliances have been reported by others, ${ }^{12}$ but fewer than $50 \%$ of dentists in this current survey discussed side-effects of the appliances with their patients. Although 30\% of dentists provided appliances, there was no standard practice for the screening of patients for sleep apnoea. Most specialists (64\%) felt that screening in primary care should include an Epworth Sleepiness Scale (Fig. 3) and an additional assessment of daytime somnolence, but some felt that Epworth alone or daytime somnolence alone was sufficient.

The dentists' criteria for referral to a sleep specialist varied from not referring at all (20\%) to referring on the patient's request, or if their partner was disturbed by the noise or if the patient had severe symptoms and an adverse quality of life (36\%). When specialists considered that an oral appliance was appropriate, most referred the patient to either an orthodontist or the patient's own dentist but there was no clear consensus.

Most dentists stated that their patients would be interested in these appliances if they were offered, but felt that they were not comfortable to provide these without further training. It might be of interest to dentists to note a position statement provided by Dental Protection Limited in December 2005 on this subject. ${ }^{13}$ In summary, they will assist dentists with any claim provided that: 1) the dentist has been trained to provide these appliances; 2 ) the patient has been appropriately assessed for OSA; 3) they have a medical referral if OSA is suspected; 4) patients have been warned

Table 7 Would you be comfortable providing patients with oral appliances for sleep apnoea or disruptive snoring?

\begin{tabular}{l|l|l|l}
\hline Category & Yes & No & No Data \\
\hline General & 19 & 57 & - \\
\hline Hospital & 4 & 8 & - \\
\hline Community & 1 & 9 & - \\
\hline Not Recorded & 1 & 2 & 1
\end{tabular}

Table 8 Would you be interested in attending a course on the dentist's role in the management of sleep disorders?

\begin{tabular}{l|l|l|l}
\hline Category & Yes & No & No Data \\
\hline General & 64 & 12 & - \\
\hline Hospital & 4 & 8 & - \\
\hline Community & 8 & 2 & - \\
\hline Not Recorded & 2 & 1 & 1
\end{tabular}

\section{Table 9 Additional comments made by dentists}

Generally favourable comments or suggestions

A list of local sleep clinics for referral would be useful.

Appliances could be offered to a limited number of patients if it is felt that this would be of benefit.

I am happy to make appliances.

I believe this is more common than is currently acknowledged.

I do not treat these cases because they do not present at my practice. However, I would be interested in learning about them and how to treat.

I don't think that patients are generally aware that these disorders can be treated by dentists. I have never been asked - but I have not offered treatment either.

I've made one appliance which worked very well. Would do it again.

Not a topic that has come up as yet. However, I would like more information on the management of such cases.

Patients have enquired about 'gum shields'. They were referred to an orthodontist who provided an appliance which proved difficult to wear.

The anti-snoring devices that we have provided have received good feedback. Device works well.

Very interested. This is an under diagnosed and under treated condition.

\section{Less favourable or uncertain}

The idea of a tool that could reduce the problem is good, but as I find with bite-raising appliances for TMJ problems, compliance rate is very low. Patients try it for a week then give up.

Currently working as NHS community dental officer. Are we able to offer this service?

I think most patients would go to their GP first.

I'd prefer to refer patients to a specialist - hospital or private.

Difficulty getting onto courses.

Cost aspects

Appliance provided after sleep clinic consultant. Cost is an issue. Lots would like to try it but can't afford it. Good success with careful patient selection.

Appliances have to be cost effective. Remember it is the partners who are disturbed. Sleep apnoea is different.

Cost could be a problem as NHS do not provide a fee.

I have offered an appliance to two patients but both declined as they considered it too expensive.

Main problem is cost. If this is perceived as a medical problem would the cost be borne by NHS?

of possible risks; and 5) an appliance is part of an integrated treatment plan if OSA is present.

The role of mandibular advancement appliances was clarified and confirmed by the Scottish Intercollegiate Guidelines Network (SIGN) in 2003 and this Guideline was endorsed by the British
Thoracic Society. ${ }^{14}$ Their recommendations are that intra-oral devices are appropriate for:

1. Snorers and patients with mild OSA with normal daytime alertness

2. An alternative therapy for patients who are unable to tolerate CPAP (continuous positive airway pressure). 


\begin{tabular}{|c|c|}
\hline \multicolumn{2}{|c|}{$\begin{array}{l}\text { How likely are you to doze off or fall asleep in the following situations, in contrast to feeling just tired? } \\
\text { This refers to your usual way of life in recent times. Even if you have not done some of these things } \\
\text { recently try to work out how they would have affected you. Use of the following scale to choose the } \\
\text { most appropriate response for each situation. }\end{array}$} \\
\hline \multicolumn{2}{|l|}{$0=$ would never doze } \\
\hline \multicolumn{2}{|l|}{1 = slight chance of dozing } \\
\hline \multicolumn{2}{|l|}{$2=$ moderate chance of dozing } \\
\hline \multicolumn{2}{|l|}{$3=$ high chance of dozing } \\
\hline Situation & Chance of dozing \\
\hline Sitting and reading & $\square$ \\
\hline Watching TV & $\square$ \\
\hline Sitting, inactive in a public place (eg a theatre or a meeting) & $\square$ \\
\hline As a passenger in a car for an hour without a break & $\square$ \\
\hline Lying down to rest in the afternoon when circumstances permit & $\square$ \\
\hline Sitting and talking to someone & $\square$ \\
\hline Sitting quietly after a lunch without alcohol & $\square$ \\
\hline In a car, while stopped for a few minutes in traffic & $\square$ \\
\hline Total: & $\square$ \\
\hline
\end{tabular}

They also recommend that intraoral devices should be monitored in order to assess the control of OSA and associated symptoms.

It will also be of interest to dentists to know that the dental team at Practitioner Services, a Division of NHS National Services Scotland (responsible for the verification and payment for treatment and services provided by NHS primary care dentists in Scotland) have indicated that an NHS fee may be available for the provision of an intra-oral appliance for the treatment of OSA if full details are provided and prior approval is sought.

In summary, the current practice of dentists and specialists in relation to dental involvement in the management of obstructive sleep apnoea and socially disruptive snoring in Scotland is varied. While specialists appear to be happy for dentists to be involved, dentists need further training in the provision of these appliances, in the use of appropriate screening tests and the possible side-effects of wearing appliances. Professionals are unclear of the funding available under the National Health Service and it is suggested that familiarity with the available clinical guidelines on patient management and the involvement of dentists could clarify the treatment options for this group of patients.

We wish to thank Mr Stephen Turner, Senior Researcher, School of Medicine, University of Dundee, for his help in obtaining the list of dentists.
1. Armstrong $M$ W, Wallace $C L$, Marais J. The effect of surgery upon the quality of life in snoring patients and their partners: a betweensubjects case-controlled trial. Clin Otolaryngol Allied Sci 1999; 24: 510-522.

2. Peker Y, Hedner J, Norum J, Kraiczi H, Carlson J. Increased incidence of cardiovascular disease in middle-aged men with obstructive sleep apnea: a 7-year follow-up. Am J Respir Crit Care Med 2002; 166: 159-165.

3. Teran-Santos J, Jimenez-Gomez A, CorderoGuevara J. The association between sleep apnea and the risk of traffic accidents. Cooperative Group Burgos-Santander. N Engl J Med 1999; 340: 847-851.

4. George C F, Smiley A. Sleep apnea \&t automobile crashes. Sleep 1999; 22: 790-795.

5. Maycock G. Sleepiness and driving: the experience of UK car drivers. J Sleep Res 1996; 5: 229-237.

6. Horne J A, Reyner L A. Sleep related vehicle accidents. BMJ 1995; 310: 565-567.

7. Ohayon M M, Guilleminault $\mathrm{C}$, Priest R G, Caulet M. Snoring and breathing pauses during sleep: telephone interview survey of a United Kingdom population sample. BMJ 1997; 314: 860-863.

8. Clark G T, Nakano M. Dental appliances for the treatment of obstructive sleep apnea. J Am Dent Assoc 1989; 118: 617-619.

9. Schmidt-Nowara W W, Meade T E, Hays M B. Treatment of snoring and obstructive sleep apnea with a dental orthosis. Chest 1991; 99: 1378-1385.

10. Cameron D A, Lyons M F, Fox D L, Banham S W. Pilot study of a semi-flexible intra-oral appliance for the control of snoring. Br Dent J 1998; 185: 304-307.

11. Stradling J R, Negus T W, Smith D, Langford B. Mandibular advancement devices for the control of snoring. Eur Respir J 1998; 11: 447-450.

12. Battagel J M, Kotecha B. Dental side-effects of mandibular advancement splint wear in patients who snore. Clin Otolaryngol 2005; 30: 149-156.

13. Dental Protection Limited. Snoring and obstructive sleep apnoea syndrome. Position statement. London: Dental Protection Ltd, 2005. http://www.dentalprotection.org/uk/news/ positionstatements/snoring/ (accessed 30 October 2008).

14. Scottish Intercollegiate Guidelines Network. Management of obstructive sleep apnoea/hypopnoea syndrome in adults. A national clinical guideline. Edinburgh: Scottish Intercollegiate Guidelines Network, 2003. Guideline 73. www.sign.ac.uk/guidelines/fulltext/73/index.html

15. Johns M W. A new method for measuring daytime sleepiness: the Epworth Sleepiness Scale. Sleep 1991; 14: 540-545. 